\title{
Bioremediation of Petroleum Hydrocarbons in Seawater: Prospects of Using Lyophilized Native Hydrocarbon-Degrading Bacteria
}

\author{
Rafaela Perdigão 1,2,*, C. Marisa R. Almeida ${ }^{1}\left(\mathbb{0}\right.$, Catarina Magalhães ${ }^{1,3}$, Sandra Ramos ${ }^{1} \oplus$, Ana L. Carolas ${ }^{4}$, \\ Bruno S. Ferreira ${ }^{4}\left(\mathbb{D}\right.$, Maria F. Carvalho ${ }^{1,2} \mathbb{D}$ and Ana P. Mucha ${ }^{1,3}$ \\ 1 CIIMAR-Interdisciplinary Centre of Marine and Environmental Research, University of Porto, \\ Terminal de Cruzeiros do Porto de Leixões, Av. General Norton de Matos, S/N, \\ 4450-208 Matosinhos, Portugal; calmeida@ciimar.up.pt (C.M.R.A.); cmagalhaes@ciimar.up.pt (C.M.) \\ ssramos@ciimar.up.pt (S.R.); mcarvalho@ciimar.up.pt (M.F.C.); amucha@ciimar.up.pt (A.P.M.) \\ 2 School of Medicine and Biomedical Sciences (ICBAS), University of Porto, \\ Rua de Jorge Viterbo Ferreira, 228, 4050-313 Porto, Portugal \\ 3 Faculty of Sciences, University of Porto (FCUP), Rua do Campo Alegre 790, 4150-171 Porto, Portugal \\ 4 Biotrend S.A., Biocant Park, Núcleo 04 Lote 2, 3060-197 Cantanhede, Portugal; alcarolas@biotrend.pt (A.L.C.); \\ bsferreira@biotrend.pt (B.S.F.) \\ * Correspondence: rafaela.mendes1@ciimar.up.pt; Tel.: +351-223-401854
}

\section{check for} updates

Citation: Perdigão, R.; Almeida, C.M.R.; Magalhães, C.; Ramos, S.; Carolas, A.L.; Ferreira, B.S.; Carvalho, M.F.; Mucha, A.P. Bioremediation of Petroleum Hydrocarbons in Seawater: Prospects of Using Lyophilized Native Hydrocarbon-Degrading Bacteria. Microorganisms 2021, 9, 2285. https:// doi.org/10.3390/microorganisms9112285

Academic Editor: Giovanni Vallini

Received: 15 September 2021

Accepted: 30 October 2021

Published: 3 November 2021

Publisher's Note: MDPI stays neutral with regard to jurisdictional claims in published maps and institutional affiliations.

Copyright: (C) 2021 by the authors. Licensee MDPI, Basel, Switzerland. This article is an open access article distributed under the terms and conditions of the Creative Commons Attribution (CC BY) license (https:// creativecommons.org/licenses/by/ $4.0 /)$
Abstract: This work aimed to develop a bioremediation product of lyophilized native bacteria to respond to marine oil spills. Three oil-degrading bacterial strains (two strains of Rhodococcus erythropolis and one Pseudomonas sp.), isolated from the NW Portuguese coast, were selected for lyophilization after biomass growth optimization (tested with alternative carbon sources). Results indicated that the bacterial strains remained viable after the lyophilization process, without losing their biodegradation potential. The biomass/petroleum ratio was optimized, and the bioremediation efficiency of the lyophilized bacterial consortium was tested in microcosms with natural seawater and petroleum. An acceleration of the natural oil degradation process was observed, with an increased abundance of oil-degraders after $24 \mathrm{~h}$, an emulsion of the oil/water layer after 7 days, and an increased removal of total petroleum hydrocarbons ( $47 \%$ ) after 15 days. This study provides an insight into the formulation and optimization of lyophilized bacterial agents for application in autochthonous oil bioremediation.

Keywords: autochthonous bioremediation; oil spills; hydrocarbons; bioaugmentation; bioremediation agent; lyophilized bacteria; biotechnology; marine environment

\section{Introduction}

Hydrocarbon pollution resulting from anthropogenic activities threatens our marine ecosystems, whether by acute events of contamination, such as oil spills, or by chronic contamination. Mass-scale oil spills have high media coverage and are extremely dangerous to the environment, pressuring governments and agencies to act fast to contain and tackle the spillage. Sometimes, a faster response might not be the most environmental-friendly or effective approach [1], as illustrated by the Deepwater Horizon oil spill in 2010, where chemical dispersants were applied on a large scale to disperse the oil, harming the wildlife [2,3]. Bioremediation technologies, on the other hand, have been considered promising ecologic alternatives to tackle oil spills, avoiding the negative implications associated with physical-chemical techniques, like the introduction of chemical dispersants or burning the spilled oil [4-6]. Bioremediation can be divided into two strategies: biostimulation (BS), by adding nutrients to the affected area to stimulate the oil-degrading metabolisms by the microbial community naturally present, and bioaugmentation (BA) where known oil-degrading microorganisms are added to increase their abundance among the local 
microbial community. A combination of these two methods has been proved to enhance hydrocarbon degradation $[4,7,8]$. Many groups of microorganisms have been reported to play a role in hydrocarbons degradation in the marine environment, such as the filamentous fungi genera Aspergillus and Penicillium [9] and the yeast genus Candida [10], nonetheless, bacteria are considered the major intervenient in hydrocarbons biodegradation at sea [11]. Members of the classes Gammaproteobacteria, Alphaproteobacteria and Actinobacteria have been isolated from seawater and marine sediment samples showing hydrocarbon bioremediation potential [12-14]. When considering the application of bioaugmentation techniques to tackle oil spills, the use of a consortium of microorganisms may be more effective than using single bacterial strains, since different groups of bacteria can metabolize different groups of hydrocarbons $[15,16]$, by producing different oil-degrading enzymes [17] and biosurfactants [18]. Previous studies $[5,19,20]$ observed a higher hydrocarbon-degrading efficiency when using a consortium of microorganisms in seawater. Furthermore, the use of autochthonous microorganisms can improve the degradation efficiency, considering that these organisms are better adapted to the environment. These microorganisms have the advantage of not competing with the natural community for the carbon source and do not cause the possible negative impact associated with the introduction of exogenous organisms [21,22]. Recently, several laboratory studies highlighted the importance and potential of using native bacterial consortia to bioremediate petroleum hydrocarbons in impacted marine environments $[5,19,20]$.

Even by doing effective laboratory experiments to test bioremediation agents or a combination of agents, the bioremediation efficiency in a real environment relies on various factors, such as environmental conditions, the concentration and chemical composition of the oil spilled, the bioavailability of hydrocarbons, the concentration of nutrients present and the time taken to develop a tailor-made solution and effective bacterial consortium to apply after the oil spill [23-25].

Regarding the application of bioremediation agents in open water systems, such as seawater, the application of free-cell bioremediation might be challenging as it might disperse in the water column [26]. To tackle this issue, some studies suggest the application of immobilized bacterial cells into carriers, biofilms or enzyme substances to enhance the hydrocarbons biodegradation performance [27-31]. Wang et al. [28] studied the application of immobilized bacteria in field tests ( 3 months), contaminated with crude oil and diesel and observed that the immobilized bacterial consortia performed better in the degradation of hydrocarbons. Hou et al. [31] observed an enhanced diesel bioremediation process by immobilizing an oil-degrading bacteria Acinetobacter sp. to a novel carrier when compared to an addition of free cells to the experiment. Despite the promising bioremediation results from these previous studies, most of the immobilized bacteria used in the process were not autochthonous for the site.

Field tests with the application of microbial agents in the marine environment evidenced the effectiveness of bioaugmentation in the removal of oil from rocks and sediments at a beach impacted by the Nakhodka oil spill (1997) [32]. There are already a few microbial products in the market to tackle oil spills, besides nutrient fertilizers and other chemical compounds prepared for biostimulation. A market study on patents of microorganisms to be applied in bioremediation carried out by Villela et al. [33], revealed that most of these patents belong to microorganisms from the Bacteria group (368 out of 500 patents). Species from the genera Pseudomonas, Rhodococcus, Acinetobacter and Bacillus are in the top 10 of bacterial bioremediation agents. However, most patents considered only individual bacterial strains or consortia of exogenous microorganisms. Regarding the use of autochthonous bacterial consortia to bioremediate petroleum hydrocarbons in seawater only one patent was found [34]. Thus, more research is needed on the identification/isolation of autochthonous bacterial strains with high petroleum biodegradation potential to increase the range of native bacterial consortia products for hydrocarbons bioremediation applications. Moreover, the procedures needed to fully use those bacterial strains after isolation, either alone or in a consortium, must be studied. This includes the optimization of biomass 
production, biomass preparation for field application and the amount of biomass needed to be introduced considering the size of the spill. To fulfil this need, and facilitate the preservation of the bacterial biomass, a lyophilization (or freeze-drying) technique can be used [35]. By doing so, the resulting bacterial product, in the form of powder, could be more easily stored and transported, at temperatures between $2{ }^{\circ} \mathrm{C}$ and $8{ }^{\circ} \mathrm{C}$, occupying less volume as opposed to in solution, and allow the direct application of the bacterial product to an oil spill. This process could also increase the "shelf-life" of the bacterial product, as bacterial cells can retain their viability after 5-35 or even 50 years from the lyophilization process [36].

Taking, as a case study, a beach located near an oil refinery, the present work aimed to (i) optimize the biomass production of three oil-degrading bacterial strains previously isolated from beach seawater and sediment, for lyophilization purposes; (ii) test the viability and hydrocarbon-degrading capacity of the lyophilized strains, individually or combined into a consortium; (iii) optimize the ratio of the bacterial consortium biomass and oil for efficient biodegradation of hydrocarbons and (iv) validate the bioremediation efficiency of the optimized lyophilized consortium in microcosms experiments with natural seawater from the case study beach.

\section{Materials and Methods}

\subsection{Growth Optimization of Hydrocarbon-Degrading Bacteria for Lyophilization}

Three bacterial strains, Rhodococcus erythropolis CPN 2, R. erythropolis CPN 3 and Pseudomonas sp. $1.7 \mathrm{~L}$, previously isolated from water and sediment collected in the beach Cabo do Mundo $\left(41^{\circ} 13^{\prime} 13.9^{\prime \prime}\right.$ N 8 $42^{\prime} 53.1^{\prime \prime}$ W), NW Portugal [37], were used in the current study due to their high potential to degrade petroleum hydrocarbons. This beach is located near an oil refinery and about $4 \mathrm{~km}$ from the Leixões Harbour (Matosinhos, Portugal). After isolation, the bacterial strains were cryopreserved at $-80{ }^{\circ} \mathrm{C}$ [8]. For the current study, laboratory growth optimization tests were initially conducted for each bacterial strain using different carbon sources alternative to hydrocarbons, namely sodium acetate, glycerol, glucose and peptone. These experiments were carried out in batch mode, in $250 \mathrm{~mL}$ Erlenmeyer flasks containing $50 \mathrm{~mL}$ of Bushnell-Haas (BH) medium (Difco) supplemented with $2 \% \mathrm{NaCl}(v / v)$ and $10 \mathrm{~g} \mathrm{~L}^{-1}$ of one of the indicated carbon sources. A bacterial inoculum was prepared for each cryopreserved bacterial strain, and individually used to inoculate the flasks at an initial biomass density of ca. 0.05 (optical density (OD), measured by spectrometry at $600 \mathrm{~nm}$ ). After selecting a suitable carbon source for biomass production of each bacterial strain (Figure S1), the bacterial strains were lyophilized. For the lyophilization process, each cryopreserved bacterial strain was first grown in $25 \mathrm{~mL}$ of Nutrient Broth (NB, Merck cat number 1054430500, $13 \mathrm{~g} \mathrm{~L}^{-1}$ ), a medium that contains peptone, supplemented with $10 \mathrm{~g} \mathrm{~L}^{-1}$ of sodium acetate, at an initial OD (at $600 \mathrm{~nm}$ ) of ca. 0.1 . All cultures were incubated in an orbital shaker $(150 \mathrm{rpm})$ at $30^{\circ} \mathrm{C}$. After this period, the cultures were centrifuged $\left(10 \mathrm{~min}, 9000 \mathrm{rpm}, 25^{\circ} \mathrm{C}\right)$ and the resulting pellet was resuspended in $30 \mathrm{~mL}$ of cryopreservation medium CP01 (Nutrient broth $13 \mathrm{~g} \mathrm{~L}^{-1}$ and Sucrose $\left.100 \mathrm{~g} \mathrm{~L}^{-1}\right)$. Tubes were left at room temperature for $1 \mathrm{~h}$ and then stored at $-80^{\circ} \mathrm{C}$. Afterward, the cells were lyophilized for $63.5 \mathrm{~h}\left(-50^{\circ} \mathrm{C}, 0.3 \mathrm{bar}\right)$, after which were stored in closed recipients and preserved at $5{ }^{\circ} \mathrm{C}$. The cell viability and the hydrocarbon degradation potential, estimated by the most probable number (MPN) method, were assessed in laboratory experiments using the lyophilized bacterial strains alone or in a consortium (Section 2.2.1).

\subsection{Evaluation of the Viability and Hydrocarbon-Degradation Potential of the Lyophilized Bacteria}

\subsubsection{Experiments with the Lyophilized Strains CPN2, CPN3, 1.7 L}

The viability and degradation potential of each lyophilized strain, alone or in a consortium, were tested in $100 \mathrm{~mL}$ serum flasks containing different media artificially contaminated with sterile petroleum (supplementary material Figure S2). The following treatments were applied: (i) sterile seawater, petroleum and lyophilized inoculum (SPI), 
(ii) sterile seawater, petroleum, lyophilized inoculum and the addition of nutrients $\left(\mathrm{KNO}_{3}\right.$ $(40 \mathrm{mM})$ and $\mathrm{KH}_{2} \mathrm{PO}_{4}(8 \mathrm{mM})$ ) (SPNI), (iii) nutrient broth, petroleum and lyophilized inoculum (NBPI). Two controls were also assembled, one with sterile seawater and petroleum and the other with sterile seawater, petroleum and nutrients (SPN). Each treatment was tested in triplicate. For the SPI, SPNI and NBPI treatments, initial suspensions of the lyophilized strains CPN 2 (2i), CPN 3 (3i) and $1.7 \mathrm{~L}$ (4i) were prepared in $250 \mathrm{~mL}$ flasks, with a medium/bacterial lyophilizate ratio of 30:0.05 $(v / w)$, where $0.05 \mathrm{~g}$ of lyophilized bacteria and a final volume of $30 \mathrm{~mL}$ of seawater were applied. The consortium (5i) was prepared in $250 \mathrm{~mL}$ flasks containing $90 \mathrm{~mL}$ of the respective media and $0.05 \mathrm{~g}$ of each lyophilized strain. After an hour of hydration, $10 \mathrm{~mL}$ of the suspension was transferred to $100 \mathrm{~mL}$ serum flasks and the nutrients were added to the SPN and SPNI treatments. In parallel, each lyophilized strain or the consortium was suspended, according to the ratio indicated above, in Bushnell-Haas (BH) medium supplemented with $2 \% \mathrm{NaCl}(v / v)$, and immediately (with no hydration period) evaluated for oil degraders abundance by the MPN method. Each treatment was tested in triplicate and with the addition of $0.25 \mathrm{~mL}$ of petroleum $(0.2 \mu \mathrm{m}$ filtered $)$. All flasks were closed with sealing caps to maintain the sterility of the medium and evaluate the hydrocarbon-degrading potential of only the lyophilized bacteria added to the media. The flasks were incubated for $24 \mathrm{~h}$ under constant agitation $(100 \mathrm{rpm})$, in the dark and at room temperature (ca. $\left.25^{\circ} \mathrm{C}\right)$. The abundance of hydrocarbon-degraders was evaluated for each condition, after one hour (T0) and $24 \mathrm{~h}$ (T1) of incubation with petroleum, by the MPN method.

\subsubsection{Experiments with Different Concentrations of the Lyophilized Consortium}

In this experiment, the consortium of the lyophilized strains was tested at different concentrations, in $100 \mathrm{~mL}$ serum flasks containing natural seawater collected at the Matosinhos beach (salinity 36, $\mathrm{pH} 8)\left(41^{\circ} 10^{\prime} 35.033^{\prime \prime} \mathrm{N} 8^{\circ} 41^{\prime} 33.605^{\prime \prime} \mathrm{W}\right)$. An initial suspension was created consisting of a mixture of $0.05 \mathrm{~g}$ of each lyophilized strain hydrated in $90 \mathrm{~mL}$ of natural seawater (6i) for one hour, corresponding to an initial concentration of $1.7 \mathrm{~g} \mathrm{~L}^{-1}$ for each lyophilized strain. Afterward, two successive tenfold dilutions were prepared in the natural seawater (7i and 8i), corresponding to final concentrations of $1.7 \times 10^{-1} \mathrm{~g} \mathrm{~L}^{-1}$ and $1.7 \times 10^{-2} \mathrm{~g} \mathrm{~L}^{-1}$ of each lyophilized strain. The experiment set up is summarized in Figure S3. The treatments SPI, SPNI and the controls SP and SPN were assembled with natural seawater, in triplicate, with the addition of $0.25 \mathrm{~mL}$ of petroleum $(0.2 \mu \mathrm{m}$ filtered) All flasks were closed and incubated for $24 \mathrm{~h}$, under constant agitation (100 rpm), in the dark and at room temperature (ca. $25^{\circ} \mathrm{C}$ ). The MPN was analyzed in the natural seawater (Ti), after one hour (T0) and $24 \mathrm{~h}$ (T1) of incubation with petroleum.

\subsection{Microcosms Bioremediation Experiment in Natural Seawater}

To evaluate the biodegradation efficiency of the optimum concentration of the lyophilized consortium in natural seawater, a microcosms experiment was assembled. The experiment was carried out in $100 \mathrm{~mL}$ serum flasks containing $10 \mathrm{~mL}$ of natural seawater collected from a beach in Matosinhos ( $\left.41^{\circ} 10^{\prime} 35.033^{\prime \prime} \mathrm{N} 8^{\circ} 41^{\prime} 33.605^{\prime \prime} \mathrm{W}\right)$, and petroleum $(0.2 \mu \mathrm{m}$ filtered) in the ratio of 20:0.5 $(v / v)$. Three different treatments were tested: (i) natural attenuation (NA) (seawater + petroleum), (ii) biostimulation (BS) (seawater + petroleum + nutrients), and (iii) a combination of biostimulation and bioaugmentation (BA) (seawater + petroleum + nutrients + lyophilized consortium). The overall scheme is represented in Figure S4. Each treatment was tested in triplicate except for NA, for which 6 additional flasks were prepared at the beginning of the experiment and preserved at $-20{ }^{\circ} \mathrm{C}$ for analysis of total petroleum hydrocarbons (TPHs) at the initial time. Considering the results obtained in the experiments of Section 2.2.2, the consortium concentration in the order of $10^{-1} \mathrm{~g} \mathrm{~L}^{-1}$ was selected as the inoculum for the BA treatment of the microcosms experiment. All flasks were closed and incubated for 15 days, under constant agitation (100 rpm), in the dark and at room temperature. The abundance of hydrocarbon-degrading bacteria in solution ( $2 \mathrm{~mL}$ collected from each flask) was analyzed for the initial natural seawater and after one hour (T0), $24 \mathrm{~h}$ (T1), 7 days (T7) and 15 days (T15) 
of incubation with petroleum. Aliquots of initial seawater and of each solution were also collected for isolation of potential oil-degrading bacterial strains, for the treatment BA at T0, T7 and T15 and for the treatments BA and BS at T15. At the end of the 15 days, the remaining solution of each treatment was stored at $-20{ }^{\circ} \mathrm{C}$ in the respective flask for TPHs analysis.

\subsection{Abundance of Hydrocarbon-Degrading Bacteria by the MPN Method}

To assess the abundance of hydrocarbon-degrading bacteria, the most probable number (MPN) method adapted from [38] as reported in Almeida et al. [4] was performed. In 96-well plates, $20 \mu \mathrm{L}$ of the sample was inoculated into $180 \mu \mathrm{L}$ sterile $\mathrm{BH}$ medium supplemented with $2 \% \mathrm{NaCl}$ together with $10 \mu \mathrm{L}$ of petroleum $(0.2 \mu \mathrm{m}$ filtered $)$, in tenfold dilutions. After two weeks of incubation at room temperature (ca. $25^{\circ} \mathrm{C}$ ), $50 \mu \mathrm{L}$ of sterilized iodonitrotetrazolium solution $\left(3 \mathrm{~g} \mathrm{~L}^{-1}\right)$ was added to each well. After an overnight incubation, positive wells (with the color violet) were registered.

\subsection{Analyses of the Total Petroleum Hydrocarbons (TPHs)}

The flasks with the remaining solution from the microcosm experiment were first defrosted. Then, $20 \mathrm{~mL}$ of tetrachloroethylene was added to each flask, and the flask was agitated to detach the petroleum from the walls and subjected to an ultrasonic bath for 15 min for hydrocarbons extraction, as described in Almeida et al. [4]. TPHs were analyzed in the extract by Fourier transform infrared spectrophotometry (Jasco FT/IR-460 Plus) as described in Almeida et al. [4]. The evaluation of TPHs was chosen as this methodology mostly quantifies saturated hydrocarbons and these types of hydrocarbons are normally the first ones to be degraded (e.g., [39]).

\subsection{Isolation of Potential Hydrocarbon-Degrading Bacteria}

A composed sample resulting from the combination, for each treatment, of aliquots collected from the triplicate flasks, was prepared, being afterward, ten-fold diluted in sterile saline solution ( $0.85 \%$ ) and spread onto M1 agar medium (1 L of seawater, $10 \mathrm{~g}$ soluble starch, $4 \mathrm{~g}$ yeast extract, $2 \mathrm{~g}$ peptone and $15 \mathrm{~g}$ agar) plates and incubated at $28{ }^{\circ} \mathrm{C}$, for 3 days. Morphologically different colonies were described and isolated by the streaking method in M1 agar. Pure colonies were preserved in $21 \%$ glycerol at $-80^{\circ} \mathrm{C}$ and biomass of each bacterial strain was collected for DNA extraction.

\subsection{Identification of Bacterial Strains}

The DNA of the bacterial strains isolated during the microcosm bioremediation experiment (Section 2.6) was extracted by using the commercial kit E.Z.N.A. ${ }^{\circledR}$ Bacterial DNA Kit (Omega, bio-tek), following the protocol provided by the supplier. For phylogenetic identification, the regions V1 to V9 of the 16S rRNA gene were amplified using the universal primers 27F (5' AGAGTTTGATCMTGGCTCAG 3') and 1492R (5' TACGGYTACCTTGTTACGACTT $3^{\prime}$ ). The PCR reaction mixture, with a final volume of $10 \mu \mathrm{L}$, contained: $5 \mu \mathrm{L}$ of Qiagen Multiplex PCR Master Mix (Qiagen, CA, USA), $1 \mu \mathrm{L}$ of each primer $(2 \mathrm{mM})$ and $3 \mu \mathrm{L}$ of DNA sample. PCR conditions were as follow: a first cycle of $15 \mathrm{~min}$ at $95^{\circ} \mathrm{C}$; followed by 30 cycles at $94{ }^{\circ} \mathrm{C}$ for $30 \mathrm{~s}, 48^{\circ} \mathrm{C}$ for $90 \mathrm{~s}$ and $72{ }^{\circ} \mathrm{C}$ for $2 \mathrm{~min}$; a final cycle at $72{ }^{\circ} \mathrm{C}$ for $10 \mathrm{~min}$. The amplified DNA samples were visualized in a $1.5 \%$ agarose gel containing SYBR Safe (Thermo Fisher Scientific, Waltham, MA, USA). PCR products were sequenced at Genomics i3S Scientific Platform (Porto, Portugal). The resulting forward and reverse 16S rRNA sequences were aligned using the Geneious software (version 11.1.4), and the consensus sequences were compared to those present in the nucleotide collection database of the National Center for Biotechnology Information (NCBI, Bethesda, MD, USA) and two other databases, to confirm the results, EZTaxon database (http:/ / www.ezbiocloud.net, accessed on 18 January 2021) and Ribosomal Database Project (https://rdp.cme.msu.edu/index.jsp, accessed on 18 January 2021). The $16 \mathrm{~S}$ rRNA gene sequences of the identified strains were deposited in GenBank (NCBI) under the accession numbers indicated in Table S1. 
To construct a phylogenetic tree, an alignment was first made with the sequences of all isolated bacterial strains and their three closest neighbor sequences in Genbank, using the MUSCLE alignment tool from the Geneious software. Then, a maximum likelihood phylogenetic tree was generated with 1000 bootstraps based on the Tamura-Nei model using the MEGA X program (Version 7.0, PA, USA) [40].

\subsection{Data Analysis}

Triplicates of MPN concentrations from the experiments with lyophilized strains and microcosm experiments were analyzed and their mean values $(n=3)$ and standard deviations calculated. The same approach was applied to the determination of the TPHs concentration in the microcosm bioremediation experiments. For both MPN and TPHs, statistical analyses were made with IBM SPSS statistics program (version 26, IBM, Armonk, NY, USA), where a non-parametric Kruskal-Wallis ANOVA multiple comparison test was applied. Significant differences were considered when p values were equal or below 0.05.

\section{Results}

\subsection{Abundance of Hydrocarbon-Degraders in the Experiments with Lyophilized Strains}

Laboratory growth optimization tests were initially conducted for each bacterial strain using carbon sources alternative to hydrocarbons, namely sodium acetate, glycerol, glucose and peptone. Results indicated that sodium acetate, glucose and peptone were good alternative carbon sources for biomass growth of the CPN2 and CPN3 strains, whilst glucose and peptone promoted the biomass growth for the 1.7 L strain (Figure S1). After obtaining this information, the bacterial strains were lyophilized as described in materials and methods (Section 2.1), to obtain a bioremediation product.

\subsubsection{Experiments with the Strains CPN2, CPN3, 1.7 L and Their Consortium}

After the lyophilization process, the viability and capacity for hydrocarbon degradation of the three lyophilized bacterial strains (CPN2, CPN3 and 1.7 L), either individually or as a consortium, was evaluated in sterile seawater. For the treatments inoculated with the lyophilized bacterial strains (SPI, SPNI and NBPI), high abundance of hydrocarbondegraders was observed after just $1 \mathrm{~h}$ of incubation with petroleum (between $10^{7}$ and $10^{11} \mathrm{MPN} / \mathrm{mL}$ ), having all strains increased after $24 \mathrm{~h}$, reaching values between $10^{9}$ and $>10^{11} \mathrm{MPN} / \mathrm{mL}$ (above the operational limit of the method). These high abundances were also observed when the lyophilized bacteria were immediately dissolved in $\mathrm{BH}$ medium, without the need of contact with petroleum. All this indicates that the lyophilized bacterial strains maintained their natural capacity to degrade petroleum hydrocarbons and that they can proliferate if this carbon source is available. In the control treatments, consisting in sterile seawater doped with petroleum and with (SPN) or without nutrients, the abundance of hydrocarbon degraders after $1 \mathrm{~h}$ and $24 \mathrm{~h}$ of incubation was approximately zero, confirming the sterility of the medium in this assay (Figure 1). Overall, the lyophilized strains presented a similar abundance of hydrocarbon degraders, for each time, across all treatments, with no statistical differences between treatments with the same lyophilized bacterial, both at T0 and T1. Within the SPI treatment, at T0, the addition of the $1.7 \mathrm{~L}$ lyophilized strain, resulted in a significantly higher MPN value, when compared to the other strains. Since the consortium of the three strains presented densities higher than $10^{11} \mathrm{MPN} / \mathrm{mL}$ and given the advantage of using diverse strains in the biodegradation of petroleum hydrocarbons, the consortium was selected for further experiments. 


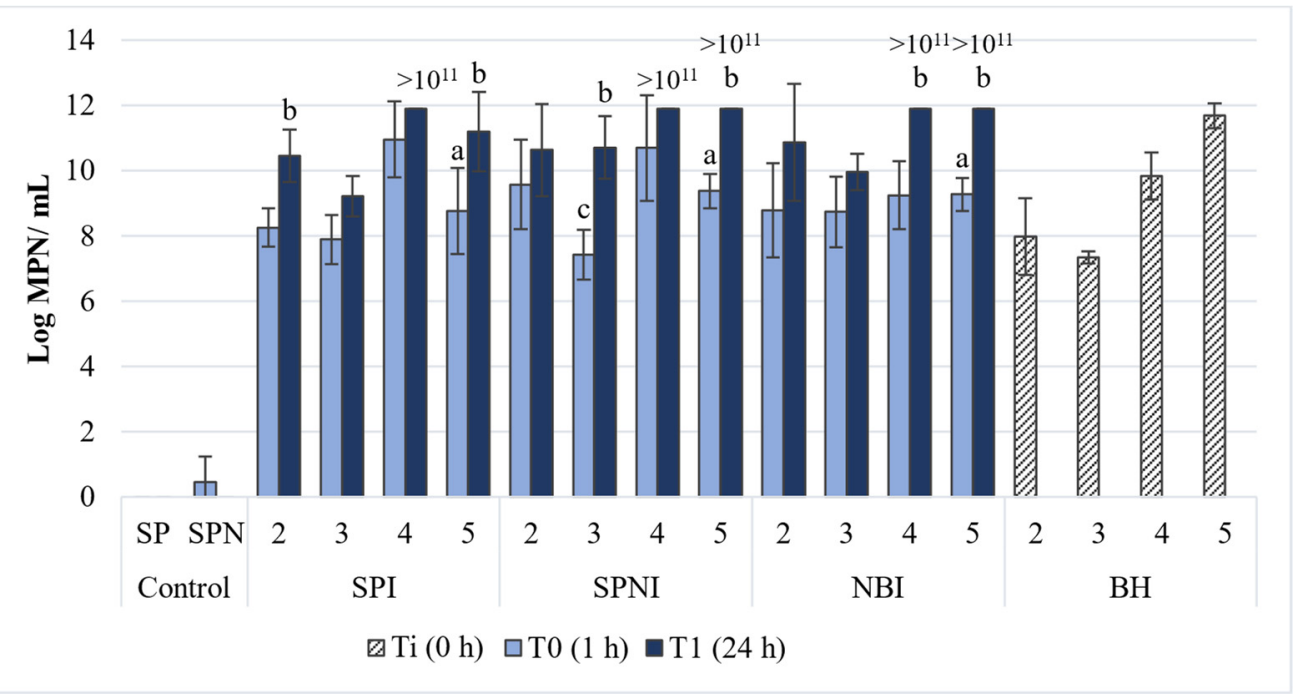

Figure 1. Abundance of hydrocarbon degraders, evaluated by the most-probable number (MPN) method, for the lyophilized bacterial strains CPN2 (2), CPN 3 (3), 1.7 L (4), and their consortium (5) (mean value, standard deviation, $n=3$ ) after direct application in $\mathrm{BH}$ medium (BHI), after $1 \mathrm{~h}(\mathrm{~T} 0)$ and after $24 \mathrm{~h}$ (T1) of incubation in the treatments SPI (sterile seawater + petroleum + inoculum), SPNI (sterile seawater + petroleum + nutrients + inoculum), NBPI (nutrient broth + petroleum + inoculum). a-significant differences comparing all treatments with the values from BHI treatment, for each lyophilized bacterium (or their consortium); b-significant differences comparing with the values from T0, within the same treatment and type of lyophilized bacteria; c-significant differences comparing different type of lyophilized bacteria, in the same treatment at T0.

\subsubsection{Experiments with Different Concentrations of the Consortium of the Three Lyophilized Strains}

The hydrocarbon-degrading potential of the consortium containing the three lyophilized bacterial strains (CPN2, CPN3 and $1.7 \mathrm{~L}$ ) at different concentrations (in the order of $1.7 \mathrm{~g}$ $\mathrm{L}^{-1}, 10^{-1} \mathrm{~g} \mathrm{~L}^{-1}$ and $10^{-2} \mathrm{~g} \mathrm{~L}^{-1}$ ) was tested in natural seawater after incubation for $1 \mathrm{~h}$ and $24 \mathrm{~h}$ with petroleum (Figure 2). The control treatments (SP and SPN) had low abundance of hydrocarbon degraders for the same period of incubation, around $10^{1} \mathrm{MPN} / \mathrm{mL}$, with no significant differences between $\mathrm{T} 0$ and T1. All treatments and consortium concentrations had significantly higher MPN values than the respective controls at T0 and T1. In both SPI and SPNI treatments, the lower the concentration of lyophilized consortium, the lower the MPN values at T0. After $24 \mathrm{~h}$ (T1), the higher concentration of the lyophilized consortium (in the order of $1.7 \mathrm{~g} \mathrm{~L}^{-1}$ ) presented an abundance of hydrocarbon degraders higher than the operational limit of the method $\left(>10^{11} \mathrm{MPN} / \mathrm{mL}\right)$, but this value was not significantly different from the other lyophilized concentrations in the SPI treatment. With the addition of nutrients, in the SPNI treatment, the two higher concentrations of the lyophilized consortium (in the order of $1.7 \mathrm{~g} \mathrm{~L}^{-1}$ and $10^{-1} \mathrm{~g} \mathrm{~L}^{-1}$ ) displayed the highest performance, with values of $10^{11} \mathrm{MPN} / \mathrm{mL}$ or higher. No significant differences were observed, comparing MPN values of each consortium concentration, between SPI and SPNI treatments, in both T0 and T1.

Based on the results of this assay, the consortium with intermediate concentration (in the order of $10^{-1} \mathrm{~g} \mathrm{~L}^{-1}$ ) was selected for the microcosms experiment since it displayed a potential similar to the consortium 10 times more concentrated to biodegrade petroleum hydrocarbons. 


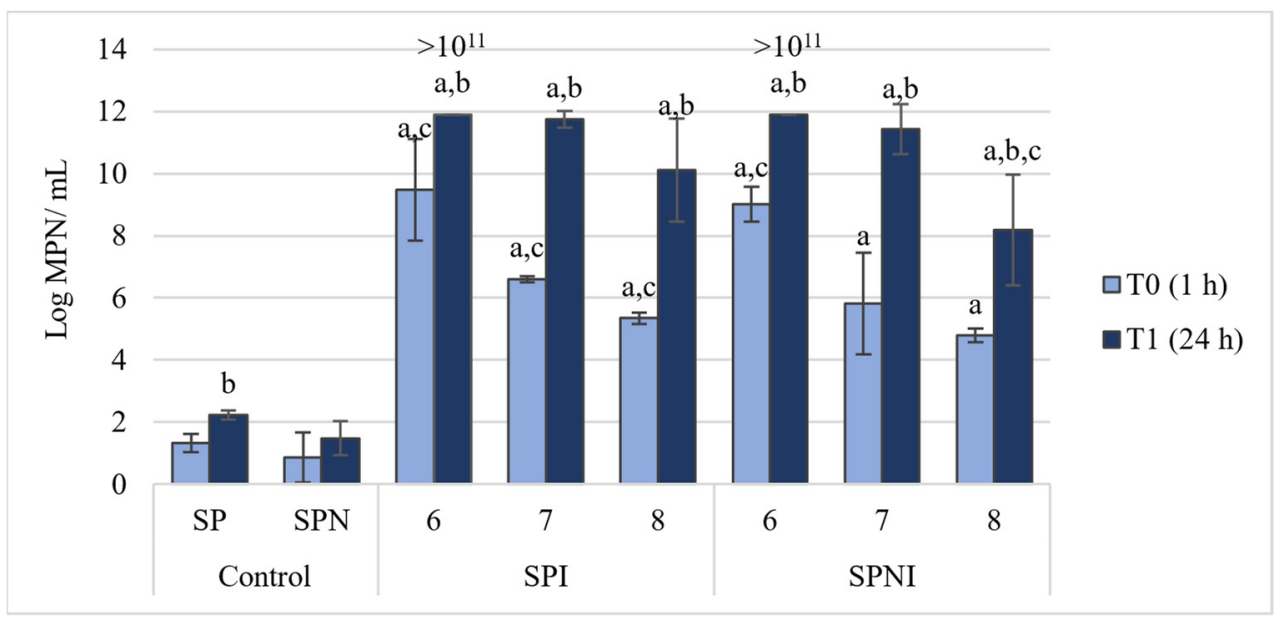

Figure 2. Abundance of hydrocarbon-degraders, evaluated by the most-probable number (MPN) method (mean value, standard deviation, $n=3$ ), in controls SP (natural seawater + petroleum) and SPN (natural seawater + petroleum + nutrients), and in treatments SPI (natural seawater + petroleum + inoculum) and SPNI (natural seawater + petroleum + nutrients + inoculum), where a consortium of three lyophilized strains (inoculum) was added to SPI and SPNI in different concentrations: 1.7 (6), $1.7 \times 10^{-1}(7), 1.7 \times 10^{-2}(8) \mathrm{g} \mathrm{L}^{-1}$. a-significant differences comparing all treatments with the respective control, at the same time; $b$-significant differences comparing with the values at $\mathrm{T} 0$, in the same treatment and concentration; c-significant differences comparing with the values from other concentrations within the same treatment, at the same time.

\subsection{Microcosm Bioremediation Experiment}

To evaluate the biodegradation efficiency of the optimized consortium (Section 3.1.2) in natural seawater, a microcosm experiment was assembled, with three treatments: natural attenuation (NA), biostimulation (BS) and bioaugmentation (BA). The hydrocarbon biodegradation efficiency was tested after $1 \mathrm{~h}, 24 \mathrm{~h}, 7 \mathrm{~d}$ and 15 days of incubation with petroleum.

For each treatment, photos were taken at the beginning and after 7 and 15 days of experiment (Figure 3). At the beginning of the experiment (T0), a clear separation between the oil slick and the medium was observed for the 3 treatments. After 7 days of experiment (T7), this separation was still observed for natural attenuation (NA) and biostimulation (BS) treatments, while for bioaugmentation (BA) treatment a clear blending between the petroleum and the medium was observed. At the end of the experiment (T15), the separation between the oil slick and the medium was still observed in NA, while for BS the blending between the petroleum and the medium was starting.

Regarding the abundance of hydrocarbon degraders (Figure 4), the bioaugmentation (BA) treatment presented, as expected, high values after $24 \mathrm{~h}$ of the experiment $\left(10^{5} \mathrm{MPN} / \mathrm{mL}\right)$, significantly higher than values in the BS treatment at the same time (in the order of $10^{1} \mathrm{MPN} / \mathrm{mL}$ ). Those high levels were only achieved in the NA and BS treatments after 7 days of the experiment. From T7 to T15, the NA treatment maintained the hydrocarbon-degraders abundance, whereas the BS treatment significantly increased the abundance of hydrocarbon degraders, reaching values close to $10^{10} \mathrm{MPN} / \mathrm{mL}$. At the end of the experiment (T15), no significant differences in terms of abundance of hydrocarbon degraders were observed between the treatments BS and BA. However, for BA treatment the values of hydrocarbon degraders were already higher than $10^{11} \mathrm{MPN} / \mathrm{mL}$ at T7, showing the tremendous potential of the bacterial consortium for the degradation of hydrocarbons. 


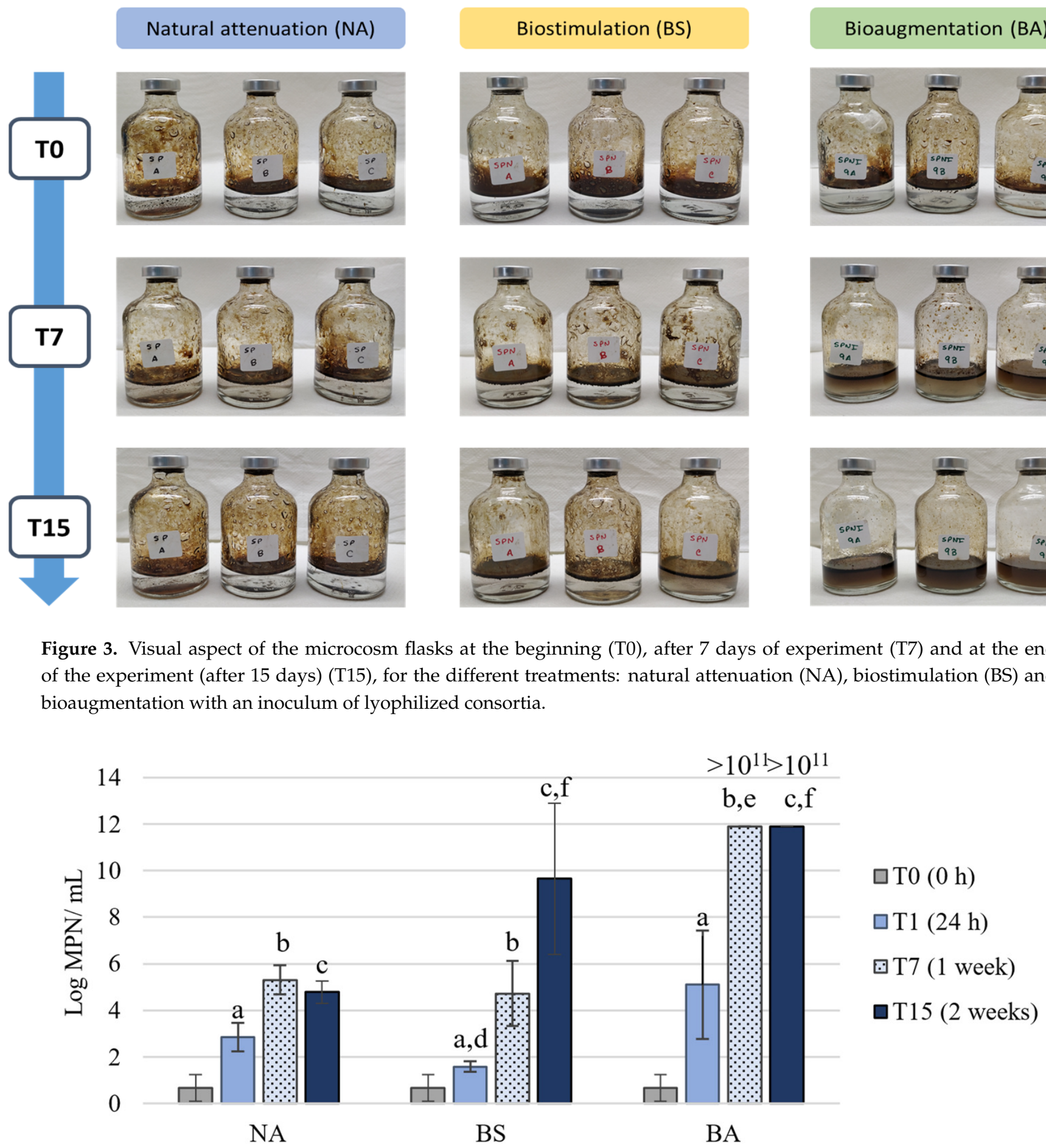

Figure 4. Abundance of hydrocarbons degraders, evaluated by the most-probable number (MPN) method, in the microcosm experiments (mean value, standard deviation, $n=3$ ) with different treatments: Natural attenuation (NA), biostimulation (BS) and bioaugmentation (BA). a - significant differences between $\mathrm{T} 1$ and $\mathrm{T} 0$, for the same treatment; $\mathrm{b}$ - significant differences between T1 and T7, for the same treatment; c-significant differences between T1 and T15, for the same treatment; $\mathrm{d}$-significant differences comparing all treatments with NA at T1; e-significant differences comparing all treatments with NA at T7; $\mathrm{f}$-significant differences comparing all treatments with NA at T15. 
After 2 weeks of the microcosm experiment (T15), the percentage of TPHs removal was evaluated for each treatment. BA treatment was able to remove the highest percentage of TPHs, $47 \%$, higher than the BS treatment $(29 \%)$ or NA $(37 \%)$, although differences were only significant between BA and BS (Figure 5). This result highlights the role of the enriched natural community, after 15 days exposed to petroleum, in the degradation of petroleum hydrocarbons. Probably the petroleum hydrocarbons initially present were gradually degraded in smaller hydrocarbons before complete degradation. Therefore, if the type of petroleum hydrocarbons had been analyzed using a chromatographic methodology, the extend of the different biodegradation levels in the three treatments could have been better shown.

100

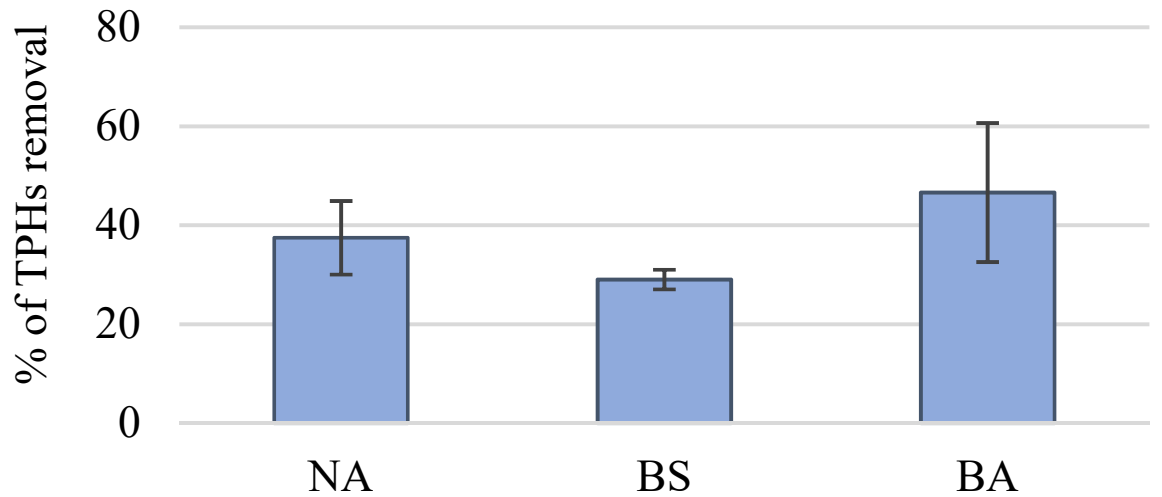

Figure 5. Removal percentage of total petroleum hydrocarbons (TPHs) in the microcosm experiments (mean value, standard deviation, $n=3$ ) for the different treatments: natural attenuation (NA), biostimulation (BS) and bioaugmentation (BA).

Bacterial strains isolated from aliquots of the natural seawater at $\mathrm{T} 0$ and of the treatments natural attenuation (NA) and biostimulation (BS) at T15, as well as of the treatment bioaugmentation (BA) at T0, T7 and T15 were identified phylogenetically (Table S1). In a total of 32 bacterial strains isolated and identified throughout the experiment, most of the obtained bacteria belong to the class Gammaproteobacteria. Nevertheless, bacteria from the class Alphaproteobacteria, Flavobacteriia and Actinobacteria were also recovered. Overall, 18 different bacterial genera were identified (Figure 6). In the natural seawater (SW) 3 different genera were found. and after a 15 day-exposure to petroleum, it was possible to recover, in the NA treatment, 5 bacterial strains distinct from the ones isolated at the same time in the BS and BA treatment. In BS, only 3 genera were recovered at T15, with a dominance of bacteria belonging to the Pseudomonas genus. 


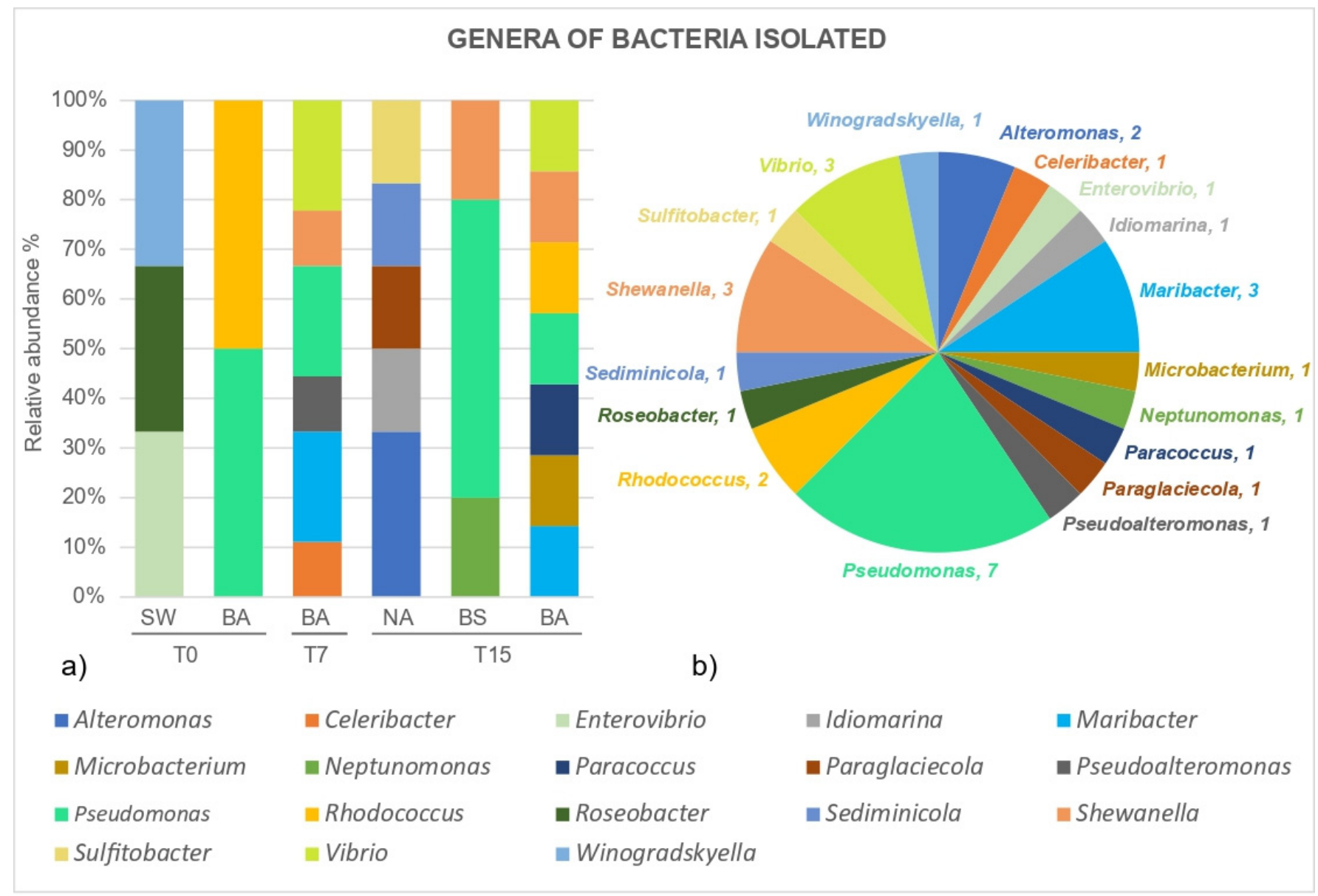

Figure 6. Genera of the bacterial strains obtained in the microcosm bioremediation experiment. (a) Relative abundance of the obtained bacterial genera in the natural seawater (SW), in the bioaugmentation (BA) treatment at the beginning (T0), after 7 days of experiment (T7) and at the end of the experiment (after 15 days) (T15), and in the natural attenuation (NA) and biostimulation (BS) treatment after 15 days (T15). (b) Total number of bacteria genera obtained in all treatments of the microcosm bioremediation experiment.

For the BA treatment, at the beginning of the experiment (T0) only the two introduced bacterial genera (Pseudomonas and Rhodococcus) were recovered, maybe due to the high density of the added inoculum used. The relative abundance of the introduced genera Pseudomonas and Rhodococcus, decreased along time in BA, starting at T0 with 50\% each, $0.22 \%$ and $0 \%$ in $\mathrm{T} 7$ and, $0.14 \%$ and $0.14 \%$ at $\mathrm{T} 15$, respectively. After one week (T7), the diversity of the genera recovered from the BA treatment increased. After 15 days (T15) the highest number of genera was recovered in the BA treatment followed by NA.

The analysis of the constructed phylogenetic tree (Figure 7) shows that both species of the lyophilized bacteria added in the BA treatments were successfully recovered at $\mathrm{T} 0$ (0BA_A, 0BA_B) and after 15 days of the experiment (15BA_A, 15BA_D). At T7 only the Pseudomonas strain was recovered (7BA_A), not being possible to recover the Rhodococcus species. Furthermore, it was possible to recover some other bacterial strains from the different treatments. These bacteria are originated from the natural seawater used in the microcosms experiments that were able to prosper in the presence of petroleum. 


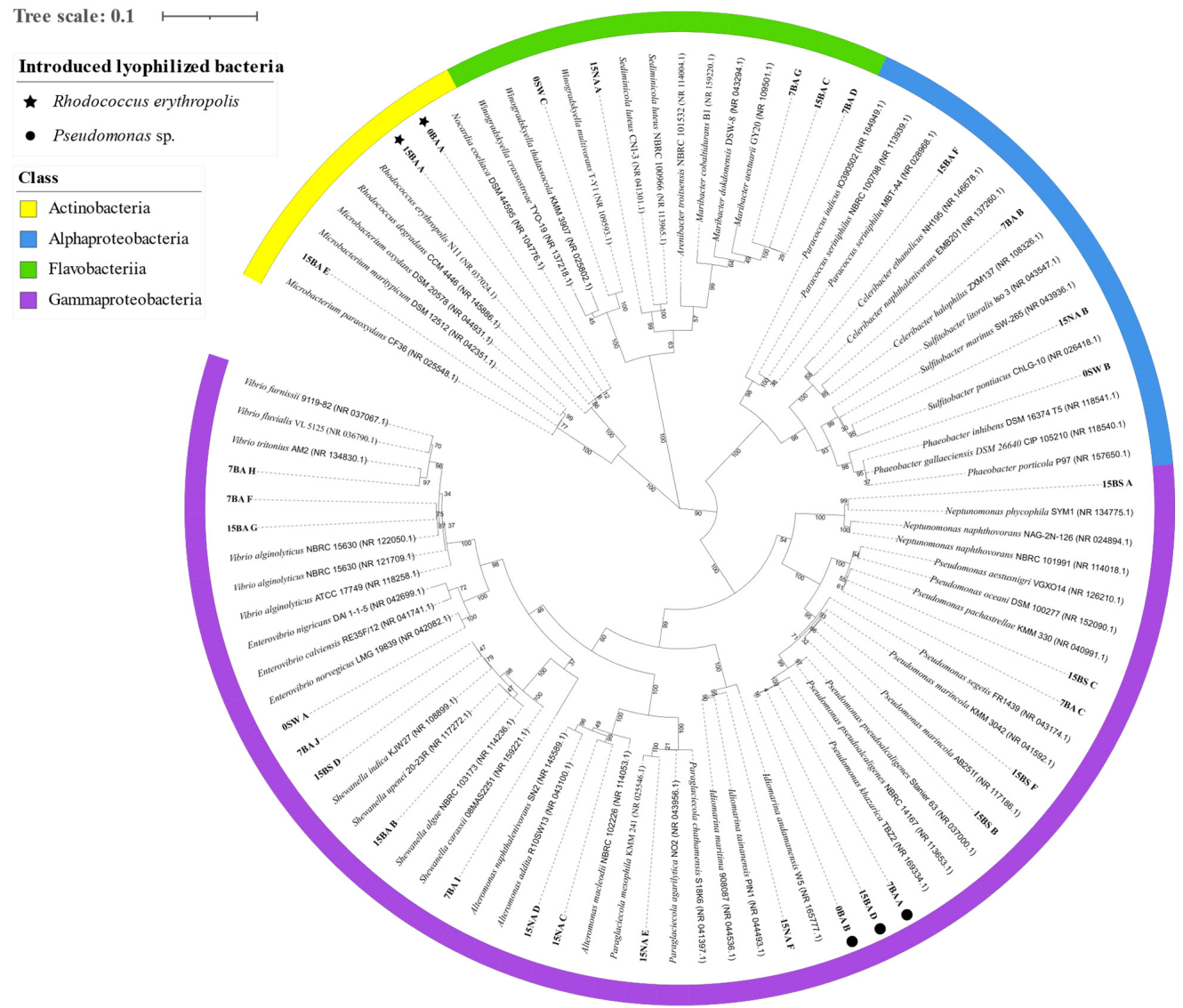

Figure 7. Phylogenetic tree of the bacterial strains isolated in the microcosm bioremediation experiment and their GenBank 3 nearest neighbors. Bacterial isolates were identified in the natural seawater (SW), in the bioaugmentation (BA) treatment at the beginning (T0), after 7 days of experiment (T7) and at the end of the experiment (after 15 days) (T15), and for natural attenuation (NA) and biostimulation (BS) treatment after 15days (T15). The maximum likelihood phylogenetic tree was performed in MEGA X using 93 nucleotide sequences, with 1410 bp length and the bootstrap method with 1000 replications. The tree is drawn to scale, with branch lengths measured in the number of substitutions per site. The GenBank accession numbers are indicated in parenthesis.

\section{Discussion}

It is widely accepted that bioremediation is an eco-friendly, cost-efficient, and effective technique to remediate oil-polluted environments and that the effectiveness of the biodegradation process can be enhanced when complemented with biostimulation and bioaugmentation [41,42]. Moreover, by choosing to apply autochthonous microorganisms in the bioremediation of an oil spill, the degradation performance can be enhanced, as these microorganisms, already adapted to the environment, will be able to compete with the natural community without disclosing the unknown consequences associated to the input of exogenous microorganisms. There are several studies reporting the potential of autochthonous bioaugmentation for bioremediation of hydrocarbons in microcosms $[4,20,43,44]$ and mesocosms experiments [45]. However, the transition from small-scale experiments to larger scale, from microcosms to mesocosms or into the field, can be challenging, due to the complexity of using natural seawater and natural environmental conditions. Another challenge with applying bioaugmentation at a larger bioremediation scale is how to assure the high bacterial biomass input needed and the ratio of biomass/petroleum for an effective bioremediation action.

In the present work, the growth of three oil-degrading bacterial strains (CPN2, CPN3, $1.7 \mathrm{~L}$ ), belonging to the genera Rhodococcus and Pseudomonas was optimized, using carbon sources alternative to hydrocarbons (sodium acetate, glucose, glycerol and peptone) for 
biomass scale-up in bioreactors. Sodium acetate is a rapidly metabolized carbon source, that has proven to enhance biomass growth in bioremediation studies without compromising the degradation ability of the bacterial strains either for hydrocarbons [8] or other organic pollutants [46-48]. Glycerol is a simple carbon source, relatively cheap and with increasing interest for the scale up of bacterial biomass production, which has been already used to grow Rhodococcus and Pseudomonas species [49,50]. Glucose and peptone were also chosen in the preliminary growth experiments as these simple carbon sources are commonly used in the scale-up of bacterial biomass production in biotechnological companies. The Rhodococcus erythropolis species CPN2 and CPN3 had higher biomass growth on sodium acetate and glucose, reaching the stationary phase after $48 \mathrm{~h}$ of incubation, while the Pseudomonas sp. (1.7L) grew better in peptone and glucose.

The biomass of these bacterial strains was then scaled-up in bioreactors and lyophilized in the biotechnological company Biotrend. By using the lyophilization technique, the bacterial cells can be preserved for longer periods of time than liquid cultures, also facilitating its storage. Laboratory tests demonstrated that the bacterial strains remained viable after the lyophilization process, without losing their biodegradation potential. In accordance, $\mathrm{Li}$ et al. [51] observed that the lyophilization process of a Bacillus strain kept the bacterial cells viable and had little effect on crude oil degradation capacity. In the present study, lyophilized strains displayed potential for hydrocarbon degradation either alone or combined in a consortium. In fact, inoculated medium showed a high abundance of hydrocarbon-degraders ( $>10^{7} \mathrm{MPN} / \mathrm{mL}$ ) after direct application of the inoculum and after $1 \mathrm{~h}$ of incubation in seawater doped with petroleum. This indicates a rapid response of the lyophilized bacterial biomass when in contact with petroleum, both in artificial and natural media. In previous work, the viability and ability of a developed lyophilized microbial degrading formula (composed of two fungal strains and one bacterial strain) to bioremediate oil spills was observed after its application in a polluted beach in China, in an in situ experiment [52]. The previous work supports a possible in situ application of lyophilized microorganisms to remediate oil spills.

In the present work, the consortium of the 3 strains presented values higher than $10^{11} \mathrm{MPN} / \mathrm{mL}$, after $24 \mathrm{~h}$ of incubation in seawater with petroleum and nutrients (SPNI). Further experiments allowed optimizing the ratio bacterial strain biomass/petroleum capable of maintaining the efficiency of hydrocarbons degradation, with high values of abundance of oil degraders $\left(10^{11} \mathrm{MPN} / \mathrm{mL}\right)$. Considering the biomass scale-up process for the application of lyophilized bacteria to a real oil spill scenario, a lower ratio of biomass/petroleum would imply fewer costs in the production process and consequently, in the bioremediation process.

The hydrocarbon-degrading performance of the optimized consortium containing the 3 lyophilized oil-degrading bacterial strains, was tested under simulated natural conditions, in microcosm experiments. The bioaugmentation with the lyophilized consortium promoted a significantly higher abundance of hydrocarbon-degraders, after $24 \mathrm{~h}$ (ca. $\left.10^{5} \mathrm{MPN} / \mathrm{mL}\right), 7$ days $\left(>10^{11} \mathrm{MPN} / \mathrm{mL}\right.$ ) and 15 days $\left(>10^{11} \mathrm{MPN} / \mathrm{mL}\right)$ of incubation with petroleum, when compared to the natural attenuation and biostimulation treatments. Visually, the bioaugmentation flasks were the only ones where emulsion of the oil/water layer occurred, an indication that the introduced bacterial consortium could accelerate the degradation process and have an important role in petroleum degradation as this blending can result in more bioavailable hydrocarbons. To corroborate this result, the introduced lyophilized bacteria (Rhodococcus erythropolis and Pseudomonas sp.) were recovered throughout the experiment, as evidenced in the phylogenetic tree. Besides being implicated in the degradation of aliphatic and aromatic hydrocarbons species from the genera Pseudomonas and Rhocococcus erythropolis have been reported to produce biosurfactants [20,53-55]. In the beginning, the introduced bacteria might have dominated the microbial community in BA, being the only species recovered (with $50 \%$ relative abundance, each). However, both introduced genera decreased their abundance along time, in BA, as other bacterial strains were isolated, as well. After 7 days, the Pseudomonas genera represented $22 \%$ of the 
isolated bacteria in BA, while the Rhodococcus was not isolated at this time. After 15 days, the genera Pseudomonas and Rhodococcus represented only $14 \%$ of relative abundance, each, in an equal percentage, however, as the other isolated bacteria genera at T15. These results might suggest an adaptation of the microbial community to a stabilization point where both the introduced bacteria and the bacteria selected from the natural seawater had a role in the degradation of petroleum, after 15 days. Probably the petroleum hydrocarbons initially present were degraded by the introduced isolates into smaller hydrocarbons that are suitable carbon sources for several other bacterial strains present in the natural seawater, thus creating the conditions for the observed rise of prokaryotic diversity. To fully understand this dynamic, a microbial community analysis could be performed in the future. By doing this, Shi et al. [56] observed that the introduced bacterial genera, were dominant in the initial phases of a bioaugmentation microcosm experiment for diesel remediation with natural seawater, but its abundance decreased with time, with the increase of other bacterial strains, a similar result to the present work.

In the present work, other bacterial species were also recovered in the microcosm treatments, after 7 and 15 days, linked in previous studies to the degradation of hydrocarbons, such as the Gammaproteobacteria Vibrio alginolyticus [57,58], Pseudoalteromonas sp. [59], Alteromonas sp. [60], Neptunomonas phycophila [61] and the Alphaproteobacteria Sulfitobacter sp. [13]. The recently described Flavobacteriia Maribacter thermophilus [62], was also recovered, and may have potential for hydrocarbon degradation, despite no other study having yet linked this species to hydrocarbon degradation.

The optimum ratio of the bacterial consortium selected in the present work led to the degradation of $47 \%$ of TPHs after 15 days of experiment, a significantly higher removal of TPHs compared with BS (29\%), and higher (but not significantly) than NA (37\%). The evaluation of TPH was chosen as this methodology includes mostly the quantification of saturated hydrocarbons and these hydrocarbons are normally the first type of hydrocarbons to be degraded, which can occur within days (e.g., [39]). This tool can easily allow evaluating the degradation potential. This result highlights the great role that the enriched natural community played in the degradation of petroleum hydrocarbons. However, these results only account for the end of the experiment (after 15 days). To evaluate if the addition of lyophilized bacteria enhanced early on, the degradation of petroleum hydrocarbons, a TPHs removal analysis could have been performed, after 7 days, when the abundance of oil degraders increased significantly in the BA, compared to other treatments. In a previous work [8], the strains CPN2 and CPN3 were tested in a consortium with 3 other strains (two Pseudomonas sp. and Acinetobacter johnsonii) and together were able to degrade $66 \%$ of TPHs in natural seawater. Contrary to this previous study, in the present work, the microcosm flasks were kept closed. The lower oxygen input to the experiment may explain the lower THPs removal since oxygen promotes the action of oxygenases, strong aliphatic hydrocarbons hydrocarbon-degrading enzymes [17,63], and isolation of the facultative anaerobe Neptunomonas phycophila [61] species. Nonetheless, the introduction of the lyophilized consortium accelerated the degradation of petroleum, a feature observed in some other studies. For instance, Li et al. [51] observed a degradation of $44.2 \%$ of total saturated hydrocarbons after 30 days of applying freeze-dried cells of a Bacillus strain to remediate petroleum. The authors refer to the potential for applying this solid inoculum in ex-situ bioremediation techniques. However, few studies have considered so far the application of lyophilized bacterial agents to remediate hydrocarbons in seawater and none has addressed its application in an autochthonous point-of-view as in our current study. This might be due to the challenges of applying free cells in open waters or coastal areas. To cope with that, some researchers propose immobilizing the bacterial agents into carriers to enhance their biodegradation efficiency [28,30,31]. For instance, Junusmin et al. [64] observed that a freeze-dried bacterial consortium (composed of two species of Bacillus and one Enterobacter species) immobilized onto different carriers could degrade up to $93 \%$ TPHs after 28 days incubation with crude oil. Luo et al. [65] reported a great potential for mesocoms field application of a freeze-dried bacterial consortium (composed of three 
Acinetobacter strains and one Gordonia species) immobilized onto a carrier, after removing $98 \%$ of petroleum from the surface of seawater, in $24 \mathrm{~h}$. So, in the future, this approach could be tested for our autochthonous lyophilized consortium.

To fully understand the applicability range of the lyophilized consortium optimized in the present work for large-scale autochthonous bioremediation, future studies should evaluate the biodegradation efficiency of the consortium when subjected to different ranges of environmental parameters like $\mathrm{pH}$, temperature, and salinity. Furthermore, monitoring the degradation of different hydrocarbon families and evaluating biosurfactants production during the bioremediation experiments could be taken into account.

The use of autochthonous microorganisms in the application of a remediation product might be key to assure the effectiveness of the bioremediation product when considering its application in a real oil-spill scenario. Nevertheless, to tackle the difficulties of applying free-cell bioremediation agents, the application of these bioremediation agents could be complemented with other existing remediation techniques, such as mechanical removal by sorbents and tested in future studies. Commercially available microbial agents for hydrocarbon bioremediation, belonging mostly to the bacteria group, includes species from the genera Pseudomonas and Rhodococcus [33]. However, there is still a low number of patents for marine oil spill bioremediation and scarce patents for autochthonous bacterial agents [34]. Hence, more research and development in this area is needed.

\section{Conclusions}

In this work, a lyophilized bioremediation agent based on three strains of hydrocarbondegrading bacteria isolated from the NW Portuguese coast was developed. The lyophilization process did not compromise the bacteria's ability to degrade hydrocarbons nor cell viability. The consortium of the three lyophilized bacteria proved to enhance the petroleum hydrocarbons degradation performance, when applied as an autochthonous bioaugmentation inoculum to microcosm experiments with natural seawater and nutrients. Moreover, these bacterial strains added to the natural seawater were recovered at the end of the experiment. To the best of our knowledge, this is the first study to develop and optimize the biomass ratio of a lyophilized bioremediation agent based on autochthonous hydrocarbon-degrading bacteria, to remediate petroleum in simulated natural conditions. Given the ubiquity of oil-degrading bacteria, the formulation of tailor-made bioremediation agents, with autochthonous bacteria, can be adapted for other geographical areas, to tackle oil spills.

Future studies should test the efficiency of the developed bioremediation agent in mesocosm and in situ experiments, test the shelf-life of the bacterial agent and test its efficiency to degrade other hydrocarbon contaminants, such as maritime fuels.

Supplementary Materials: The following are available online at https:/ / www.mdpi.com/article/10 .3390 / microorganisms9112285/s1, Figure S1: Biomass growth (mean value, standard deviation, $n=3$ ) of the bacterial isolates CPN2, CPN3 and $1.7 \mathrm{~L}$ with different carbon sources $\left(10 \mathrm{~g} \cdot \mathrm{L}^{-1}\right)$, Figure S2: Representative scheme of the experiment with the lyophilized strains CPN2 (2i), CPN3 (3i), 1.7 L (4i) and a consortium (5i), in the controls SP (sterile seawater + petroleum), SPN (sterile seawater + petroleum + nutrients) and the treatments SPI (sterile seawater + petroleum + inoculum), SPNI (sterile seawater + petroleum + nutrients + inoculum), NBPI (nutrient broth + petroleum + inoculum) and BHI (bushnell-haas + inoculum), Figure S3: Representative scheme of the experiment with the controls SP (natural seawater + petroleum), SPN (natural seawater + petroleum + nutrients) and with different concentrations of the consortium of the lyophilized strain: $6 \mathrm{i}\left(1.7 \mathrm{~g} \mathrm{~L}^{-1}\right), 7 \mathrm{i}\left(1.7 \times 10^{-1} \mathrm{~g} \mathrm{~L}^{-1}\right)$ and $8 \mathrm{i}\left(1.7 \times 10^{-2} \mathrm{~g} \mathrm{~L}^{-1}\right)$, applied to the treatments SPI (natural seawater + petroleum + inoculum) and SPNI (natural seawater + petroleum + nutrients + inoculum), Figure S4: Representative scheme of the microcosms experiments with natural seawater (SW), petroleum and the optimum concentration of the consortium of lyophilized strains $7 \mathrm{i}\left(1.7 \times 10^{-1} \mathrm{~g} \mathrm{~L}^{-1}\right)$, with the treatments natural attenuation, bioaugmentation and bioaugmentation and Table S1: Phylogenetic identification of bacterial strains isolated in the microcosms bioremediation experiment for the natural seawater at T0 (OSW) and for the different treatments: natural attenuation (NA) and biostimulation (BS) at T15, and bioaugmentation (BA) at T0, T7 and T15. 
Author Contributions: Conceptualization, R.P., C.M.R.A., M.F.C. and A.P.M.; methodology, R.P., A.L.C. and B.S.F.; validation, R.P., C.M.R.A., M.F.C. and A.P.M.; formal analysis, R.P.; investigation, R.P., C.M.R.A., M.F.C. and A.P.M.; resources, C.M.R.A., C.M., S.R., M.F.C. and A.P.M.; writingoriginal draft preparation, R.P.; writing-review and editing, C.M.R.A., C.M., S.R., B.S.F., M.F.C. and A.P.M.; supervision, C.M.R.A., M.F.C. and A.P.M.; project administration, A.P.M.; funding acquisition, C.M.R.A., C.M., S.R., M.F.C. and A.P.M. All authors have read and agreed to the published version of the manuscript.

Funding: This research was partially supported by the project BIOREM-Bioremediation of hydrocarbon pollutants by autochthonous microorganisms in aquatic environment, PTDC/BTA-GES/32186/2017 and POCI-01-0145-FEDER-032186, supported by Fundo Europeu de Desenvolvimento Regional (FEDER) through COMPETE2020-Programa Operacional da Competitividade e Internacionalização (POCI) and FCT/MCTES by national funds through FCT-Foundation for Science and Technology within the scope of UIDB/04423/2020 and UIDP/04423/2020; and by the PhD fellowship attributed to Rafaela Perdigão with the reference 2020.04689.BD financed by FCT.

Institutional Review Board Statement: Not applicable.

Informed Consent Statement: Not applicable.

Data Availability Statement: The data presented in this study are available in the current article and the respective Supplementary Materials.

Acknowledgments: Part of the samples analyzed for this study were collected under the Project Spilless-First line response to oil spills based on native microorganisms cooperation (Reference EASME/EMFF/2016/1.2.1.4/010) financed by the Executive Agency for Small and Medium-sized Enterprises (EASME) delegated by the European Commission; and under the project ROSM- Robotic Oil Spill Mitigation (Reference POCI-01-0145-FEDER-24055), supported by North Portugal Regional Operational Programme (NORTE 2020), under the PORTUGAL 2020 Partnership Agreement, through the European Regional Development Fund (ERDF).

Conflicts of Interest: The authors declare no conflict of interest. The funders had no role in the design of the study; in the collection, analyses, or interpretation of data; in the writing of the manuscript, or in the decision to publish the results.

\section{References}

1. Crisafi, F.; Genovese, M.; Smedile, F.; Russo, D.; Catalfamo, M.; Yakimov, M.; Giuliano, L.; Denaro, R. Bioremediation technologies for polluted seawater sampled after an oil-spill in Taranto Gulf (Italy): A comparison of biostimulation, bioaugmentation and use of a washing agent in microcosm studies. Mar. Pollut. Bull. 2016, 106, 119-126. [CrossRef]

2. Barron, M.G. Ecological Impacts of the Deepwater Horizon Oil Spill: Implications for Immunotoxicity. Toxicol. Pathol. 2012, 40, 315-320. [CrossRef]

3. Atlas, R.M.; Hazen, T.C. Oil biodegradation and bioremediation: A tale of the two worst spills in U.S. history. Environ. Sci Technol. 2011, 45, 6709-6715. [CrossRef] [PubMed]

4. Almeida, C.M.; Reis, I.; Couto, M.N.; Bordalo, A.A.; Mucha, A.P. Potential of the microbial community present in an unimpacted beach sediment to remediate petroleum hydrocarbons. Env. Sci. Pollut. Res. Int. 2013, 20, 3176-3184. [CrossRef]

5. Li, X.; Zhao, L.; Adam, M. Biodegradation of marine crude oil pollution using a salt-tolerant bacterial consortium isolated from Bohai Bay, China. Mar. Pollut. Bull. 2016, 105, 43-50. [CrossRef] [PubMed]

6. Priya, A.; Manab Sarma, P.; Lal, B. Isolation and characterization of Candida vishwanathiistrain TERI MS1 for degradation of petroleum hydrocarbons in marine environment. Desalination Water Treat. 2016, 57, 22099-22106. [CrossRef]

7. Nikolopoulou, M.; Pasadakis, N.; Kalogerakis, N. Evaluation of autochthonous bioaugmentation and biostimulation during microcosm-simulated oil spills. Mar. Pollut. Bull. 2013, 72, 165-173. [CrossRef]

8. Perdigão, R.; Almeida, C.M.R.; Santos, F.; Carvalho, M.F.; Mucha, A.P. Optimization of an Autochthonous Bacterial Consortium Obtained from Beach Sediments for Bioremediation of Petroleum Hydrocarbons. Water 2021, 13, 66. [CrossRef]

9. Maamar, A.; Lucchesi, M.-E.; Debaets, S.; Nguyen van Long, N.; Quemener, M.; Coton, E.; Bouderbala, M.; Burgaud, G.; Matallah-Boutiba, A. Highlighting the Crude Oil Bioremediation Potential of Marine Fungi Isolated from the Port of Oran (Algeria). Diversity 2020, 12, 196. [CrossRef]

10. Zinjarde, S.; Pant, A. Hydrocarbon degraders from tropical marine environments. Mar. Pollut. Bull. 2002, 44, 118-121. [CrossRef]

11. Leahy, J.G.; Colwell, R.R. Microbial degradation of hydrocarbons in the environment. Microbiol. Rev. 1990, 54, 305-315. [CrossRef]

12. Djahnit, N.; Chernai, S.; Catania, V.; Hamdi, B.; China, B.; Cappello, S.; Quatrini, P. Isolation, characterization and determination of biotechnological potential of oil-degrading bacteria from Algerian centre coast. J. Appl. Microbiol. 2019, 126, 780-795. [CrossRef] 
13. Harwati, T.U.; Kasai, Y.; Kodama, Y.; Susilaningsih, D.; Watanabe, K. Characterization of diverse hydrocarbon-degrading bacteria isolated from Indonesian seawater. Microbes Environ. 2007, 22, 412-415. [CrossRef]

14. Wang, W.; Zhong, R.; Shan, D.; Shao, Z. Indigenous oil-degrading bacteria in crude oil-contaminated seawater of the Yellow sea, China. Appl. Microbiol. Biotechnol. 2014, 98, 7253-7269. [CrossRef] [PubMed]

15. Hosokawa, R.; Nagai, M.; Morikawa, M.; Okuyama, H. Autochthonous bioaugmentation and its possible application to oil spills. World J. Microbiol. Biotechnol. 2009, 25, 1519-1528. [CrossRef]

16. Varjani, S.J. Microbial degradation of petroleum hydrocarbons. Bioresour. Technol. 2017, 223, 277-286. [CrossRef]

17. Fuentes, S.; Mendez, V.; Aguila, P.; Seeger, M. Bioremediation of petroleum hydrocarbons: Catabolic genes, microbial communities, and applications. Appl. Microbiol. Biotechnol. 2014, 98, 4781-4794. [CrossRef] [PubMed]

18. Souza, E.C.; Vessoni-Penna, T.C.; de Souza Oliveira, R.P. Biosurfactant-enhanced hydrocarbon bioremediation: An overview. Int. Biodeterior. Biodegrad. 2014, 89, 88-94. [CrossRef]

19. Dehvari, M.; Ghafari, S.; Haghighifard, N.J.; Jorfi, S. Petroleum Contaminated Seawater Detoxification in Microcosm by Halotolerant Consortium Isolated from Persian Gulf. Curr. Microbiol. 2021, 78, 95-106. [CrossRef]

20. Pereira, E.; Napp, A.P.; Allebrandt, S.; Barbosa, R.; Reuwsaat, J.; Lopes, W.; Kmetzsch, L.; Staats, C.C.; Schrank, A.; Dallegrave, A. Biodegradation of aliphatic and polycyclic aromatic hydrocarbons in seawater by autochthonous microorganisms. Int. Biodeterior. Biodegrad. 2019, 145, 104789. [CrossRef]

21. Fodelianakis, S.; Antoniou, E.; Mapelli, F.; Magagnini, M.; Nikolopoulou, M.; Marasco, R.; Barbato, M.; Tsiola, A.; Tsikopoulou, I.; Giaccaglia, L.; et al. Allochthonous bioaugmentation in ex situ treatment of crude oil-polluted sediments in the presence of an effective degrading indigenous microbiome. J. Hazard. Mater. 2015, 287, 78-86. [CrossRef]

22. Tao, K.; Liu, X.; Chen, X.; Hu, X.; Cao, L.; Yuan, X. Biodegradation of crude oil by a defined co-culture of indigenous bacterial consortium and exogenous Bacillus subtilis. Bioresour. Technol. 2017, 224, 327-332. [CrossRef]

23. Das, N.; Chandran, P. Microbial degradation of petroleum hydrocarbon contaminants: An overview. Biotechnol. Res. Int. 2011, 2011, 941810. [CrossRef]

24. Ivshina, I.B.; Kuyukina, M.S.; Krivoruchko, A.V.; Elkin, A.A.; Makarov, S.O.; Cunningham, C.J.; Peshkur, T.A.; Atlas, R.M.; Philp, J.C. Oil spill problems and sustainable response strategies through new technologies. Environ. Sci. Process. Impacts 2015, 17, 1201-1219. [CrossRef]

25. Xu, X.; Liu, W.; Tian, S.; Wang, W.; Qi, Q.; Jiang, P.; Gao, X.; Li, F.; Li, H.; Yu, H. Petroleum Hydrocarbon-Degrading Bacteria for the Remediation of Oil Pollution Under Aerobic Conditions: A Perspective Analysis. Front. Microbiol. 2018, 9, 2885. [CrossRef]

26. Partovinia, A.; Rasekh, B. Review of the immobilized microbial cell systems for bioremediation of petroleum hydrocarbons polluted environments. Crit. Rev. Environ. Sci. Technol. 2018, 48, 1-38. [CrossRef]

27. Dai, X.; Lv, J.; Yan, G.; Chen, C.; Guo, S.; Fu, P. Bioremediation of intertidal zones polluted by heavy oil spilling using immobilized laccase-bacteria consortium. Bioresour. Technol. 2020, 309, 123305. [CrossRef]

28. Wang, X.; Liu, Y.; Song, C.; Yuan, X.; Zhang, Q.; Miao, Y. Application Analysis of Immobilized Bioremediation Preparation in Oil Spill Contaminated Shore. In IOP Conference Series: Earth and Environmental Science; IOP Publishing: Bristol, UK, 2020.

29. Alessandrello, M.J.; Tomás, M.S.J.; Raimondo, E.E.; Vullo, D.L.; Ferrero, M.A. Petroleum oil removal by immobilized bacterial cells on polyurethane foam under different temperature conditions. Mar. Pollut. Bull. 2017, 122, 156-160. [CrossRef]

30. Chen, C.-H.; Whang, L.-M.; Pan, C.-L.; Yang, C.-L.; Liu, P.-W.G. Immobilization of diesel-degrading consortia for bioremediation of diesel-contaminated groundwater and seawater. Int. Biodeterior. Biodegrad. 2017, 124, 62-72. [CrossRef]

31. Hou, D.; Shen, X.; Luo, Q.; He, Y.; Wang, Q.; Liu, Q. Enhancement of the diesel oil degradation ability of a marine bacterial strain by immobilization on a novel compound carrier material. Mar. Pollut. Bull. 2013, 67, 146-151. [CrossRef]

32. Tsutsumi, H.; Kono, M.; Takai, K.; Manabe, T.; Haraguchi, M.; Yamamoto, I.; Oppenheimer, C. Bioremediation on the shore after an oil spill from the Nakhodka in the Sea of Japan. III. Field tests of a bioremediation agent with microbiological cultures for the treatment of an oil spill. Mar. Pollut. Bull. 2000, 40,320-324. [CrossRef]

33. Villela, H.D.M.; Peixoto, R.S.; Soriano, A.U.; Carmo, F.L. Microbial bioremediation of oil contaminated seawater: A survey of patent deposits and the characterization of the top genera applied. Sci. Total Environ. 2019, 666, 743-758. [CrossRef] [PubMed]

34. Elisabeth Helmke, B.D.; Birte Gerdes, B.D.J.; Juergens, B.D.K.; Reuter, L.D. Bioremediation Method for Accelerated Biological Decomposition of Petroleum Hydrocarbons in Sea-Iced Covered Polar Regions, and Bacteria and Enzyme Mixtures as Agents for Carrying out Said Method. U.S. Patent 8,444,962, 21 May 2013.

35. Adams, G. The Principles of Freeze-Drying. In Cryopreservation and Freeze-Drying Protocols; Day, J.G., Stacey, G.N., Eds.; Humana Press: Totowa, NJ, USA, 2007; pp. 15-38.

36. Kupletskaya, M.; Netrusov, A. Viability of lyophilized microorganisms after 50-year storage. Microbiology 2011, 80, 850-853. [CrossRef]

37. Gouveia, V. Bioremediation of Oil Along the Nw Portuguese Coast-the Role of Autochthonous Microorganisms. Master's Thesis, School of Medicine and Biomedical Sciences, University of Porto, Porto, Portugal, 2015.

38. Wrenn, B.A.; Venosa, A.D. Selective enumeration of aromatic and aliphatic hydrocarbon degrading bacteria by a most-probablenumber procedure. Can. J. Microbiol. 1996, 42, 252-258. [CrossRef] [PubMed]

39. Head, I.M.; Jones, D.M.; Röling, W.F. Marine microorganisms make a meal of oil. Nat. Rev. Microbiol. 2006, 4, 173-182. [CrossRef] 
40. Kumar, S.; Stecher, G.; Li, M.; Knyaz, C.; Tamura, K. MEGA X: Molecular evolutionary genetics analysis across computing platforms. Mol. Biol. Evol. 2018, 35, 1547-1549. [CrossRef] [PubMed]

41. Roy, A.; Dutta, A.; Pal, S.; Gupta, A.; Sarkar, J.; Chatterjee, A.; Saha, A.; Sarkar, P.; Sar, P.; Kazy, S.K. Biostimulation and bioaugmentation of native microbial community accelerated bioremediation of oil refinery sludge. Bioresour. Technol. 2018, 253, 22-32. [CrossRef]

42. Tyagi, M.; da Fonseca, M.M.R.; de Carvalho, C. Bioaugmentation and biostimulation strategies to improve the effectiveness of bioremediation processes. Biodegradation 2011, 22, 231-241. [CrossRef] [PubMed]

43. Reis, I.; Almeida, C.M.; Magalhaes, C.M.; Cochofel, J.; Guedes, P.; Basto, M.C.; Bordalo, A.A.; Mucha, A.P. Bioremediation potential of microorganisms from a sandy beach affected by a major oil spill. Environ. Sci. Pollut. Res. 2014, 21, 3634-3645. [CrossRef] [PubMed]

44. Santisi, S.; Catalfamo, M.; Bonsignore, M.; Gentile, G.; Di Salvo, E.; Genovese, M.; Mahjoubi, M.; Cherif, A.; Mancini, G.; Hassanshahian, M. Biodegradation ability of two selected microbial autochthonous consortia from a chronically polluted marine coastal area (Priolo Gargallo, Italy). J. Appl. Microbiol. 2019, 127, 618-629. [CrossRef]

45. Hassanshahian, M.; Emtiazi, G.; Caruso, G.; Cappello, S. Bioremediation (bioaugmentation/biostimulation) trials of oil polluted seawater: A mesocosm simulation study. Mar. Environ. Res. 2014, 95, 28-38. [CrossRef]

46. Alexandrino, D.A.M.; Ribeiro, I.; Pinto, L.M.; Cambra, R.; Oliveira, R.S.; Pereira, F.; Carvalho, M.F. Biodegradation of mono-, diand trifluoroacetate by microbial cultures with different origins. New Biotechnol. 2018, 43, 23-29. [CrossRef]

47. Santos, F.; Mucha, A.P.; Alexandrino, D.A.M.; Almeida, C.M.R.; Carvalho, M.F. Biodegradation of enrofloxacin by microbial consortia obtained from rhizosediments of two estuarine plants. J. Environ. Manag. 2019, 231, 1145-1153. [CrossRef] [PubMed]

48. Duarte, P.; Almeida, C.M.R.; Fernandes, J.P.; Morais, D.; Lino, M.; Gomes, C.R.; Carvalho, M.F.; Mucha, A.P. Bioremediation of bezafibrate and paroxetine by microorganisms from estuarine sediment and activated sludge of an associated wastewater treatment plant. Sci. Total Environ. 2019, 655, 796-806. [CrossRef] [PubMed]

49. Poblete-Castro, I.; Wittmann, C.; Nikel, P.I. Biochemistry, genetics and biotechnology of glycerol utilization in Pseudomonas species. Microb. Biotechnol. 2020, 13, 32-53. [CrossRef] [PubMed]

50. Sriwongchai, S.; Pokethitiyook, P.; Pugkaew, W.; Kruatrachue, M.; Lee, H. Optimization of lipid production in the oleaginous bacterium Rhodococcus erythropolis growing on glycerol as the sole carbon source. Afr. J. Biotechnol. 2012, 11, 14440-14447. [CrossRef]

51. Li, H.; Li, Y.; Bao, M.; Li, S. Solid inoculants as a practice for bioaugmentation to enhance bioremediation of hydrocarbon contaminated areas. Chemosphere 2020, 263, 128175. [CrossRef]

52. Yan, F.; Wang, Y. Remediation of marine pollution by microorganisms in the comprehensive management of coastal zones. J. Coast. Res. 2018, 239-244. [CrossRef]

53. Peng, F.; Liu, Z.; Wang, L.; Shao, Z. An oil-degrading bacterium: Rhodococcus erythropolis strain 3C-9 and its biosurfactants. J. Appl. Microbiol. 2007, 102, 1603-1611. [CrossRef]

54. Luong, T.M.; Ponamoreva, O.N.; Nechaeva, I.A.; Petrikov, K.V.; Delegan, Y.A.; Surin, A.K.; Linklater, D.; Filonov, A.E. Characterization of biosurfactants produced by the oil-degrading bacterium Rhodococcus erythropolis S67 at low temperature. World J. Microbiol. Biotechnol. 2018, 34, 20. [CrossRef]

55. Mohanram, R.; Jagtap, C.; Kumar, P. Isolation, screening, and characterization of surface-active agent-producing, oil-degrading marine bacteria of Mumbai Harbor. Mar. Pollut. Bull. 2016, 105, 131-138. [CrossRef]

56. Shi, K.; Zhang, Q.; Xue, J.; Chen, X.; Chen, Y.; Qiao, Y.; Yang, Y.; Sun, J. Study on the degradation performance and bacterial community of bioaugmentation in petroleum-pollution seawater. J. Environ. Chem. Eng. 2020, 8, 103900. [CrossRef]

57. Imron, M.F.; Titah, H.S. Optimization of diesel biodegradation by Vibrio alginolyticus using Box-Behnken design. Environ. Eng. Res. 2018, 23, 374-382. [CrossRef]

58. Feknous, N.; Branes, Z.; Batisson, I.; Amblard, C. Growth of indigenous bacteria Vibrio alginolyticus and Dietzia sp. isolated from the east coast of Algeria in the presence of monoaromatic hydrocarbons. Environ. Prot. Eng. 2019, 45, 127-137. [CrossRef]

59. Hedlund, B.P.; Staley, J.T. Isolation and characterization of Pseudoalteromonas strains with divergent polycyclic aromatic hydrocarbon catabolic properties. Environ. Microbiol. 2006, 8, 178-182. [CrossRef] [PubMed]

60. Jin, H.M.; Kim, J.M.; Lee, H.J.; Madsen, E.L.; Jeon, C.O. Alteromonas as a key agent of polycyclic aromatic hydrocarbon biodegradation in crude oil-contaminated coastal sediment. Environ. Sci. Technol. 2012, 46, 7731-7740. [CrossRef]

61. Diéguez, A.L.; Pichon, P.; Balboa, S.; Magnesen, T.; Romalde, J.L. Complete characterization of new isolates of Neptunomonas phycophila leads to emend its description and opens possibilities of biotechnological applications. MicrobiologyOpen 2017, 6, e00519. [CrossRef] [PubMed]

62. Hu, J.; Yang, Q.Q.; Ren, Y.; Zhang, W.W.; Zheng, G.; Sun, C.; Pan, J.; Zhu, X.F.; Zhang, X.Q.; Wu, M. Maribacter thermophilus sp. nov., isolated from an algal bloom in an intertidal zone, and emended description of the genus Maribacter. Int. J. Syst. Evol. Microbiol. 2015, 65 Pt 1, 36-41. [CrossRef]

63. Venosa, A.D.; Zhu, X. Biodegradation of Crude Oil Contaminating Marine Shorelines and Freshwater Wetlands. Spill Sci. Technol. Bull. 2003, 8, 163-178. [CrossRef] 
64. Junusmin, K.I.; Manurung, B.S.; Darmayati, Y. Bioremediation of Oil-Contaminated Sediment by Hydrocarbonoclastic Bacterial Consortium Immobilized in Different Types of Carrier. In Proceedings of the 5th International Symposium on Applied Chemistry (ISAC), Tangerang, Indonesia, 23-24 October 2019. Available online: https://aip.scitation.org/doi/abs/10.1063/1.5134620 (accessed on 10 September 2021).

65. Luo, Q.; Hou, D.; Jiang, D.; Chen, W. Bioremediation of marine oil spills by immobilized oil-degrading bacteria and nutrition emulsion. Biodegradation 2021, 32, 165-177. [CrossRef] 